\title{
Torque Ripple Suppression of Rounded Square Permanent Magnet DC Motor by the Harmonic Injection method
}

\author{
Fayun $\mathrm{Qi}^{1}$, Xiaoming-Wang ${ }^{2}$ \\ ${ }^{I}$ Department of Electrical Engineering, Harbin Institute of Technology, Harbin, \\ China \\ ${ }^{2}$ Department of Electrical Engineering, Harbin Institute of Technology, Harbin \\ 150001, China; \\ qifayun@163.com,xmw2002@hit.edu.cn
}

\begin{abstract}
The previous study of PM motor torque ripple is generally considered that the current distortion is the root cause of torque ripple of PMDC motor, and it is AC motor or brushless motor, not considered the effect of EMF and PMDC motor. To solve the problem, using the voltage harmonic injection method to suppress the PMDC motor torque ripple, considered the effect of EMF and PMDC motor. Base on the theory model of round square PMDC torque ripple suppression method, apply the FEM method to analyze the current and torque ripple, the improvement target is the minimum of torque and current ripple, compare the injection voltage harmonic with different optimization targets, The study provide theoretical and simulation basis to make round square torque ripple suppression sample and achieve the torque ripple suppression target.
\end{abstract}

Keywords: Round square PM motor; Torque ripple suppression; voltage Harmonic, Harmonic injection

\section{Introduction}

Cylindrical PMDC motor has been widely used as DC drive motor. However, the square installation space can not be fully utilized. Rounded square motor breaks through the traditional design of the cylindrical motor, increases the effective diameter of the rotor, increases output than conventional motor by $(17-20) \%$ with the same square mounting space.

There are many method to reduce the PMDC motor torque ripple. according to the previous study result, it is mainly two types method, the first is optimize the motor structure to reduce the motor torque ripple, for example, magnet shape optimization, pole arc coefficient improvement, skew armature and so on, but it is limited by the application status, sometime can not used, also reduce the motor performance, it is limited by the actual situation [10]. The second is reduce the torque ripple through control method, it can reduce the motor torque ripple without loss performance, for example, cogging torque compensation for flux-switching permanent magnet motor based on current harmonics injection, Torque ripple suppression of permanent magnet synchronous motor by the harmonic injection, but previous study is focus on the BLDC, PMSM motor and current optimization [9], it has not study focus on the PMDC motor and impact by EMF.

For this question, this paper propose a new harmonic injection method to reduce the rounded square PMDC motor torque ripple after considered the EMF. Base on the build theoretical modal, the optimize object is minimum torque ripple, design the injection voltage harmonic, suppress the torque ripple, verify the effectiveness of this method to reduce the torque ripple, according to the FEA analysis result of current and torque ripple. 


\section{Formatting Your Paper Rounded Square PMDC Motor Structure and Torque Ripple}

\subsection{Curve and Cylindrical PMDC Motor Structure}

Curve and cylindrical PMDC motor structure is as Figure 2.1. The analyzed curve and cylindrical motor parameters are as shown in Table 2.1.

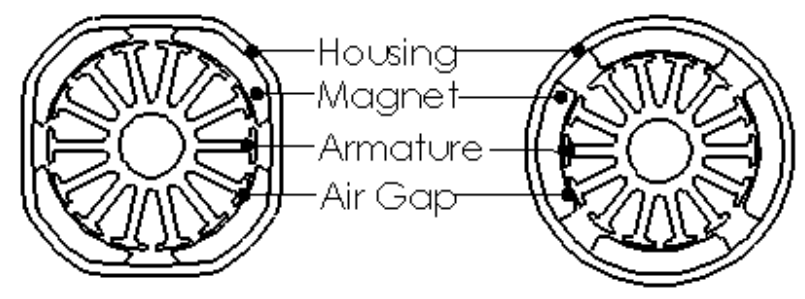

Figure 2.1 Curve and Cylindrical PMDC Motor Structure

Table 2.1 Curve and Cylindrical Motor Parameters

\begin{tabular}{|l|l|l|l|l|l|}
\hline PAR & pole & slot & $\begin{array}{l}\text { Stator } \\
\text { dimension } \\
\text { type }\end{array}$ & $\begin{array}{l}\text { Rotor } \\
\text { diameter } \\
(\mathrm{mm})\end{array}$ & $\begin{array}{l}\text { Armature } \\
\text { length } \\
(\mathrm{mm})\end{array}$ \\
\hline Curve motor & 4 & 14 & $33 \times 33$ & 26.4 & 40 \\
\hline $\begin{array}{l}\text { Cylindrical } \\
\text { motor }\end{array}$ & 4 & 14 & 33 & 23.4 & 40 \\
\hline
\end{tabular}

\subsection{Rounded Square PMDC Motor Torque Ripple Analysis}

For a given motor the torque can be expressed as

$$
T=K_{t} \Phi I
$$

Where $\mathrm{T}$ is motor torque, $K_{t}$ is torque constant, $\Phi$ is air gap magnetic flux, the period of motor torque ripple $N_{t}$ is decided by the slots number $N_{s}$ and $N_{p}$ poles number $[3,9,11]$.

$$
N_{t}=\frac{N_{S}}{H C F\left(N_{S} N_{p}\right)}
$$

Where HCF is the greatest common divisor.

For this rounded square PMDC motor, $N_{t}=7$,

Torque ripple mechanical angle can be expressed as

$$
\theta_{t}=\frac{360^{\circ}}{N_{t} N} 12.857^{\circ}
$$

The main torque ripple order is 28 and harmonics, torque can be expressed as

$$
T=T_{0}+T_{28}+T_{56}+\cdots
$$


Where $T_{0}$ is torque steady constant, $T_{28}$ is 28 order harmonics of torque ripple, can be expressed as

$$
T_{28}=T_{A 28} \sin \left(28 \theta_{r}+\varphi_{T 28}\right)
$$

$T_{56}$ is 56 order harmonics of torque ripple, can be expressed as

$$
T_{56}=T_{A 56} \sin \left(56 \theta_{r}+\varphi_{T 56}\right)
$$

Where $T_{A 28}$ is 28 order harmonic amplitude of torque ripple, $T_{A 56}$ is 56 order harmonic amplitude of torque ripple, $\varphi_{T 28}$ is 28 order harmonic phase angle of torque ripple, $\varphi_{T 56}$ is 56 order harmonic phase angle of torque ripple, $\theta_{r}$ is rotor position angle.

From above theory model, for a given motor, the torque ripple harmonic order is decided by the slots and poles number, and it is related with magnet shape, armature slot opening coefficient, winding number and son on. The toque ripple and harmonic is special frequency, phase angle and amplitude curve, for the study of reduced the torque ripple by motor structure optimization is not discussion in this paper, this paper is focus on the reduce torque ripple by harmonics injection method.

\section{Harmonic Injection Analytical Model}

In the actual situation, most power source is voltage power source for the PMDC motor, so the research target is inject voltage harmonic to reduce the torque ripple, the voltage balance equation can be expressed as [12].

$$
U=E+I R
$$

Vector relationship as below figure

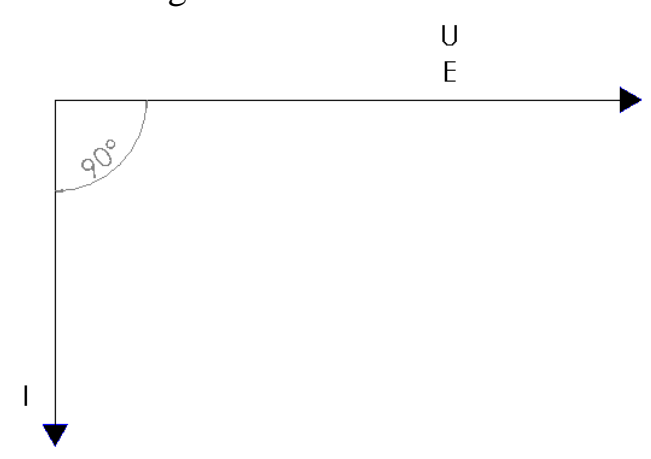

\section{Figure 3.1. Voltage, EMF and Current Vector Relationship (without Inductance)}

According to the Fourier transform method, the voltage can be expressed as [1]

$$
U=U_{0}+U_{28}+U_{56}+\cdots
$$

Where $U_{0}$ is voltage steady constant, $U_{28}$ is 28 order voltage ripple, can be expressed as 


$$
U_{28}=U_{A 28} \sin \left(28 \theta_{r}+\varphi_{U 28}\right)
$$

Where $U_{56}$ is 56 order voltage ripple, can be expressed as

$$
U_{56}=U_{A 56} \sin \left(56 \theta_{r}+\varphi_{U 56}\right)
$$

Where $\mathrm{U}$ is power source voltage, $\mathrm{E}$ is EMF of motor, $\mathrm{I}$ is branch current, $\mathrm{R}$ is branch resistance, $\varphi_{U 28}$ is 28 order voltage ripple phase angle, $\varphi_{U 56}$ is 56 order voltage ripple phase angle.

Flux $\Phi$ can be expressed as

$$
\begin{aligned}
& \Phi=\Phi_{0}+\Phi_{28}+\Phi_{56}+\cdots \\
& \Phi_{28}=\Phi_{A 28} \sin \left(28 \theta_{r}+\varphi_{\Phi 28}\right) \\
& \Phi_{56}=\Phi_{A 56} \sin \left(56 \theta_{r}+\varphi_{\Phi 28}\right)
\end{aligned}
$$

Where $\Phi_{28}$ is 28 order flux ripple phase angle, $\Phi_{56}$ is 56 order flux ripple phase. EMF can be expressed as

$$
E=E_{0}+E_{28}+E_{56}+\cdots
$$

Where $E_{0}$ is voltage steady constant, $E_{28}$ is 28 order voltage ripple, can be expressed as

$$
E_{28}=E_{A 28} \sin \left(28 \theta_{r}+\varphi_{E 28}\right)
$$

$E_{56}$ is 56 order voltage ripple, can be expressed as

$$
E_{56}=E_{A 56} \sin \left(56 \theta_{r}+\varphi_{E 56}\right)
$$

$\varphi_{E 28}$ is 28 order of EMF ripple phase angle, $\varphi_{E 56}$ is 56 order of EMF ripple phase angle,

The branch current can be expressed as

$$
\begin{aligned}
& I=I_{0}+I_{28}+I_{56}+\cdots \\
& I_{28}=I_{A 28} \sin \left(28 \theta_{r}+\varphi_{I 28}\right) \\
& I_{56}=I_{A 56} \sin \left(56 \theta_{r}+\varphi_{I 56}\right)
\end{aligned}
$$

$\varphi_{I 28}$ is 28 order of branch current ripple phase angle, $\varphi_{I 56}$ is 56 order of branch current ripple phase angle,

The torque can be expressed as

$$
T=K_{t}\left(\Phi_{0}+\Phi_{28}+\Phi_{56}\right)\left(I_{0}+I_{28}+I_{56}\right)
$$

Extract the torque ripple is related with 28 order harmonic torque ripple 


$$
T_{28}=K_{t} I_{28}\left(\Phi_{0}+\Phi_{28}+\Phi_{56}\right)+K_{t} \Phi_{28}\left(I_{0}+I_{56}\right)
$$

When

$$
\begin{aligned}
& I_{28}=0 \\
& T_{28}=K_{t} \Phi_{28}\left(I_{0}+I_{56}\right)
\end{aligned}
$$

From equation(22), Because $\Phi_{28} \neq 0$

so the $T_{28} \neq 0$. It is proof when $I_{28}=0$, the $T_{28} \neq 0$, verify the conclusion, when the current ripple is minimum the torque ripple is not minimum.

from the equation (22), if $T_{28}=0$, the current can be express as

$$
I_{28 /}=\frac{-\Phi_{28}\left(I_{0}+I_{56}\right)}{\Phi}
$$

Where

$$
\Phi=\int E d t
$$

So

$$
\begin{aligned}
& U_{28}=E_{28}+I_{28} R \\
& U_{28}=\left(E_{28}+\frac{-\Phi_{28}\left(I_{0}+I_{56}\right)}{\Phi} R\right) \\
& U_{A 28} \sin \left(28 \theta_{r}+\varphi_{28}\right)=\left(E_{A 28}+\frac{-\Phi_{28}\left(I_{0}+I_{56}\right)}{\Phi} R\right) \sin \left(28 \theta_{r}+\varphi_{28}\right)
\end{aligned}
$$

From equation (24)-(26), when the injection voltage harmonic amplitude express as

Initial phase angle is $\varphi_{28}$, injection frequency is $28 \omega$,

The 28 order torque ripple is minimum.

When considered the inductance impact, the voltage balance equation expressed as

$$
T=E+I R+L \frac{d i}{d t}
$$

The vector figure as

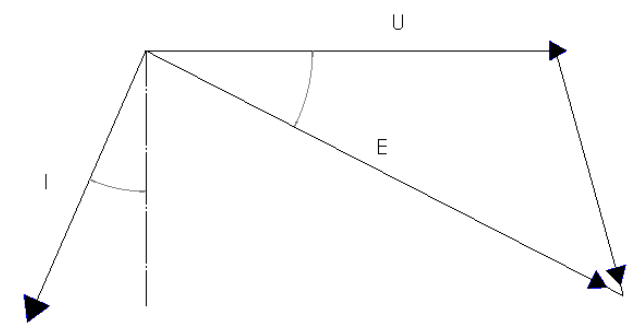

Figure 3.2. Voltage, EMF and Current Vector Relationship (with Inductance) 


$$
\begin{aligned}
& U_{A 28} \sin \left(28 \theta_{r}+\varphi_{28}+\phi_{1}\right)= \\
& \left(E_{A 28}+\frac{-\int E_{28}\left(I_{0}+I_{56}\right) d t}{\int E d t} R+L \frac{-\Phi_{28}\left(I_{0}+I_{56}\right)}{\Phi} d t\right) \sin \left(28 \theta_{r}+\varphi_{28}+\phi_{1}\right)
\end{aligned}
$$

From above figure, the current hysteresis angle is $\varphi_{1}$, the equation (26) can be expressed as

When the amplitude of 28 order voltage as equation (28), initial phase angle is $\varphi_{28}+\phi_{1}$, injection frequency is $28 \omega$, the 28 order torque ripple is minimum.

IV . the injection voltage harmonic phase angle, amplitude, frequency impact on the torque and current ripple

From the equation (28), the torque and current ripple is related with injection voltage phase angle, amplitude, frequency. The final harmonic injection method is control the injection voltage harmonic to reduce the torque ripple. So find the optimize parameter and the relationship is very critical [5].

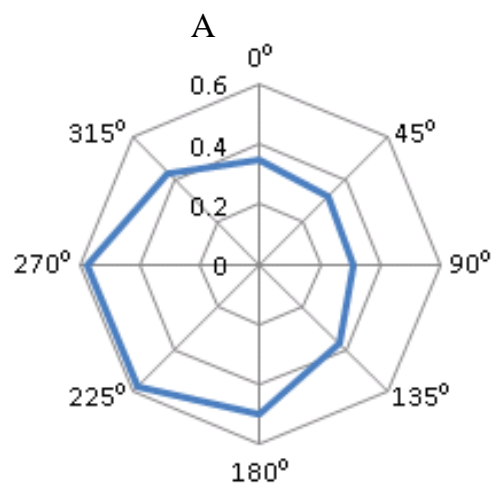

Figure 5.1. 28 Order Harmonic Current Amplitude vs 28 Order Voltage Harmonic Initial Phase Angle

The 28 order current ripple is along with the 28 order harmonic injection voltage initial phase angle, when the amplitude and frequency is constant, the initial phase angle is 90 degree, the current ripple is minimum value.

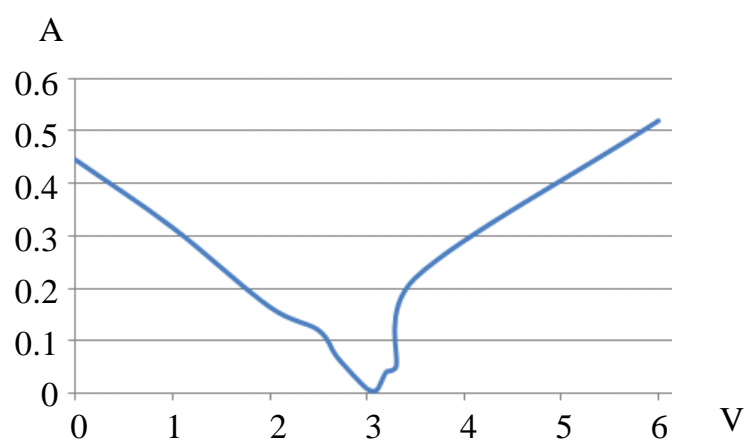

Figure 5.2. 28 Order Harmonic Current Amplitude vs 28 Order Voltage Harmonic Amplitude 
The 28 order current ripple is along with the 28 order harmonic injection voltage amplitude, when the initial phase angle and frequency is constant, the amplitude is $3 \mathrm{~V}$, the current ripple is minimum value.

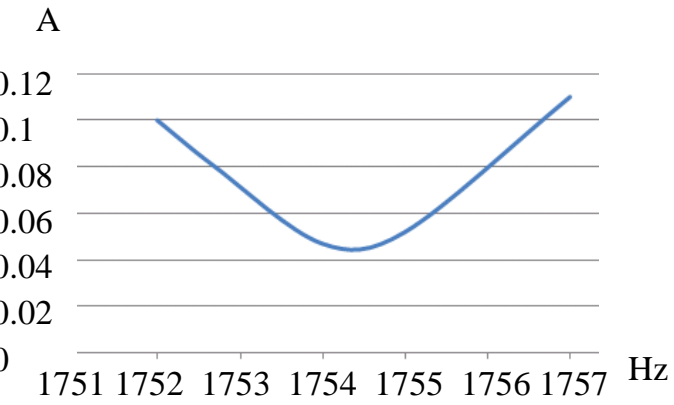

Figure 5.3. 28 Order Harmonic Current Amplitude vs 28 Order Voltage Harmonic Frequency

The 28 order current ripple is along with the 28 order harmonic injection voltage frequency, when the amplitude and initial phase angle is constant, the frequency is $1754 \mathrm{~Hz}$, the current ripple is minimum value.

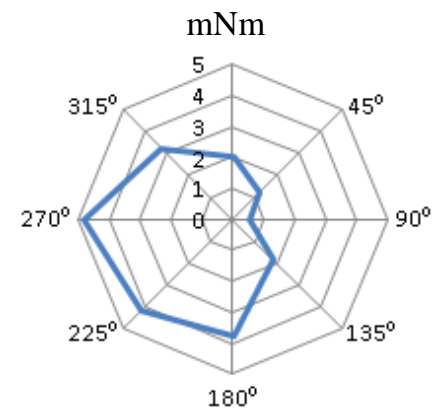

Figure 5.4. 28 Order Harmonic Torque Amplitude vs 28 Order Voltage Harmonic Initial Phase Angle

The 28 order torque ripple is along with the 28 order harmonic injection voltage initial phase angle, when the amplitude and frequency is constant, the initial phase angle is 90 degree, the current ripple is minimum value.

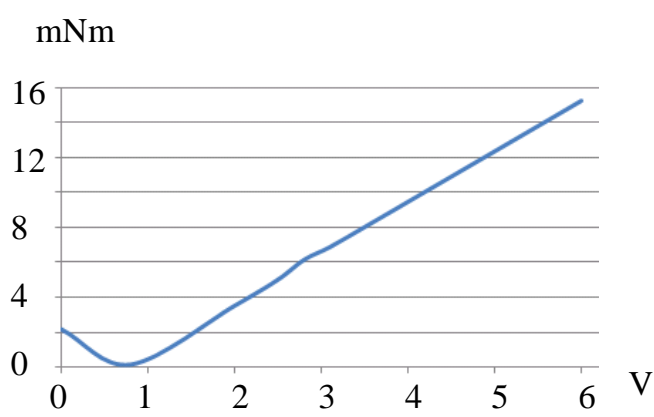

Figure 5.5. 28 Order Harmonic Torque Amplitude vs 28 Order Voltage Harmonic Amplitude 
The 28 order current ripple is along with the 28 order harmonic injection voltage amplitude, when the initial phase angle and frequency is constant, the amplitude is $1 \mathrm{~V}$, the current ripple is minimum value.

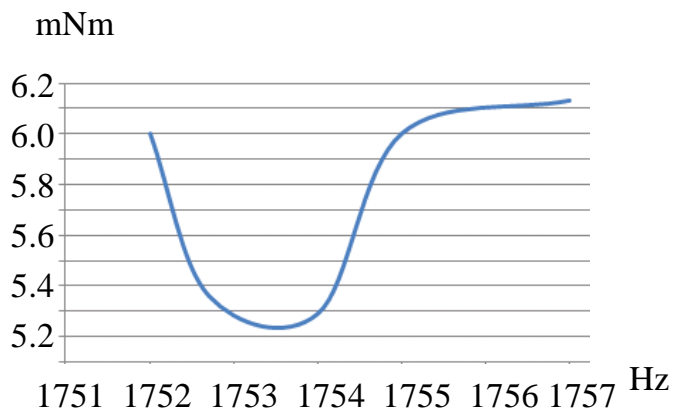

Figure 5.4. 28 Order Harmonic Torque Amplitude vs 28 Order Voltage Harmonic Frequency

The 28 order current ripple is along with the 28 order harmonic injection voltage frequency, when the amplitude and initial phase angle is constant, the frequency is $1754 \mathrm{~Hz}$, the current ripple is minimum value.

From above analysis, the 28 order harmonic current and torque ripple is along with the injection harmonic voltage amplitude, frequency, initial phase angle, and only have one minimum value, verify the conclusion, when injection special harmonic voltage the current and torque ripple can achieve the minimum value.

\section{Harmonics Injection Simulation Result}

According to the theoretical and simulation result, for verify the effectiveness of harmonics injection method to reduce the torque ripple, this paper use ANSOFT software to make FEA simulation analysis, the analysis object is 28 order harmonics torque ripple. Rounded square PMDC motor simulation modal as below

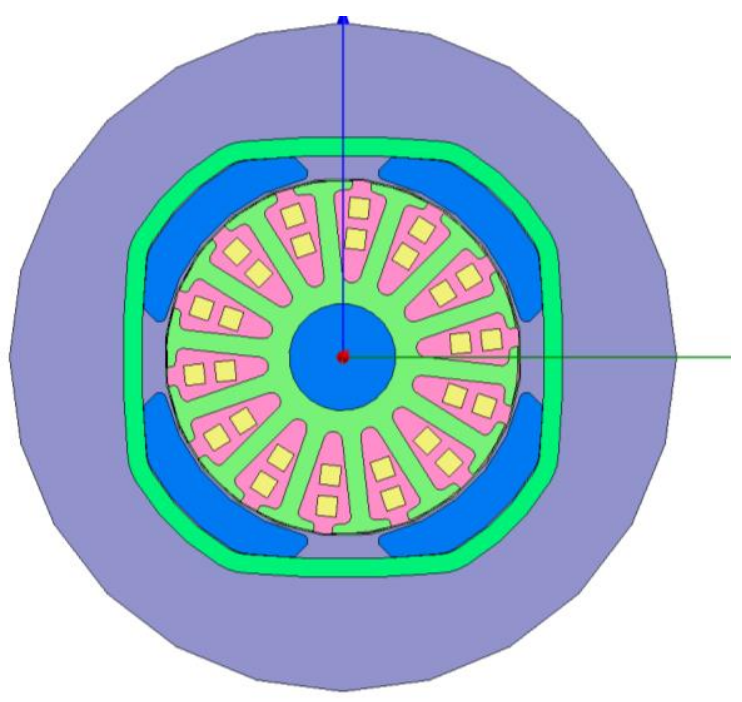

Figure 4.1. Rounded Square PMDC Motor FEA Modal

Simulate the rounded square PMDC motor torque and current ripple on $100 \mathrm{mNm}$ load condition as below 


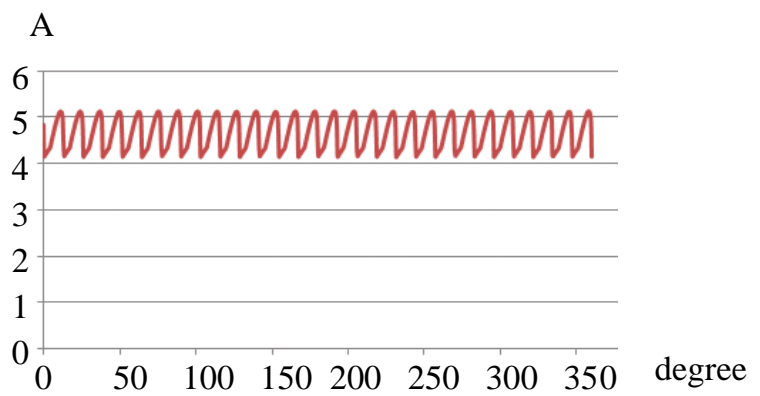

Figure 4.6. Round Square Motor Current Ripple Curve (on Load)

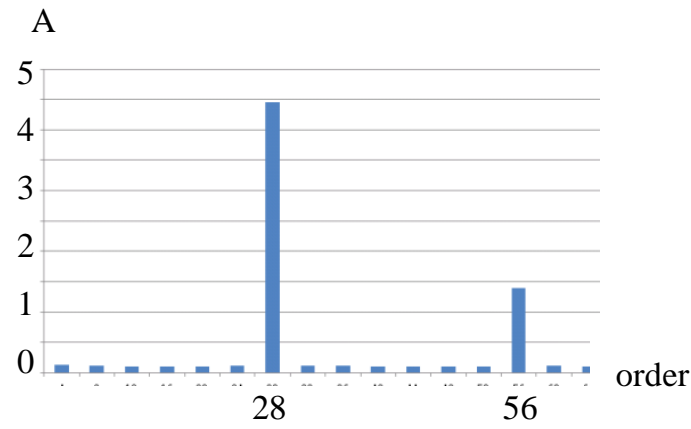

Figure 4.7. Round Square Motor Current Ripple Fourier (on Load)

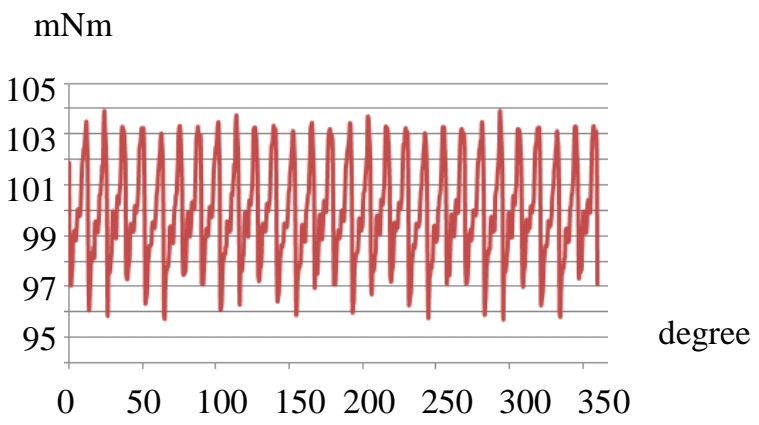

Figure 4.8. Round Square Motor Torque Ripple Curve (on Load)

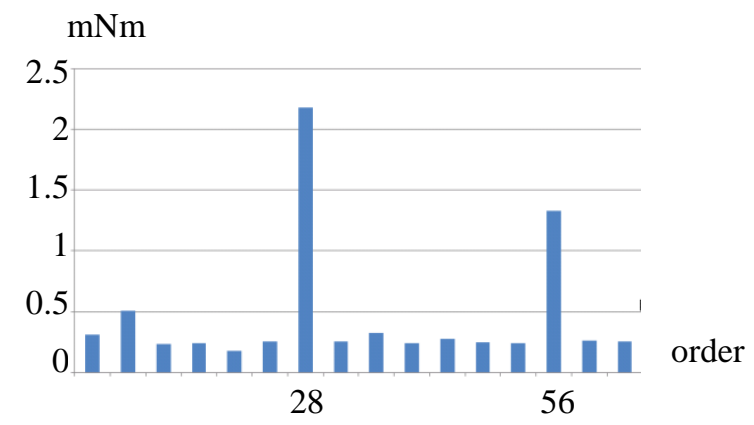

Figure 4.8. Round Square Motor Torque Ripple Fourier (on Load)

on load condition, the torque ripple will be change as the current ripple, it is proof that the voltage harmonic injection will impact on the torque ripple, 
This paper is focus on the 28 order harmonic torque ripple improvement.

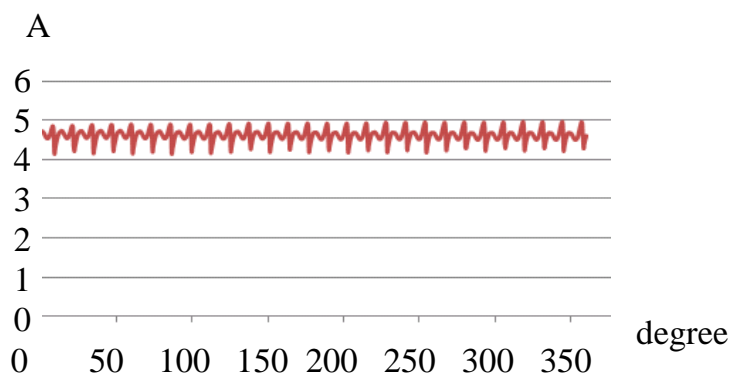

Figure 4.10. Round Square Motor Current Ripple Curve (Minimum Current Ripple)

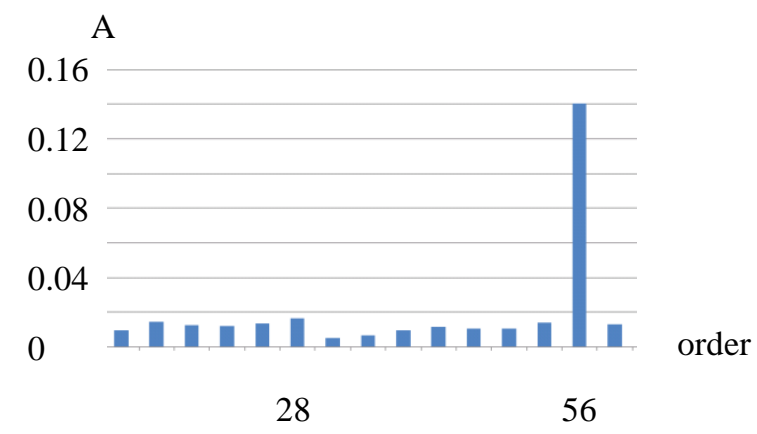

Figure 4.11. Round Square Motor Current Ripple Fourier (Minimum Current Ripple)

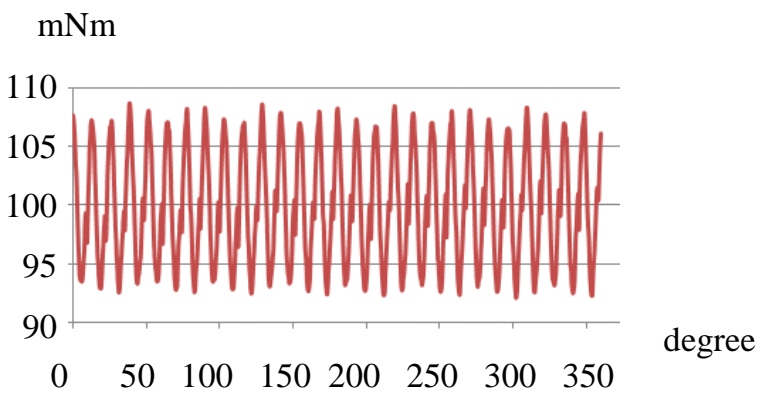

Figure 4.12. Round Square Motor Torque Ripple Curve (Minimum Current Ripple)

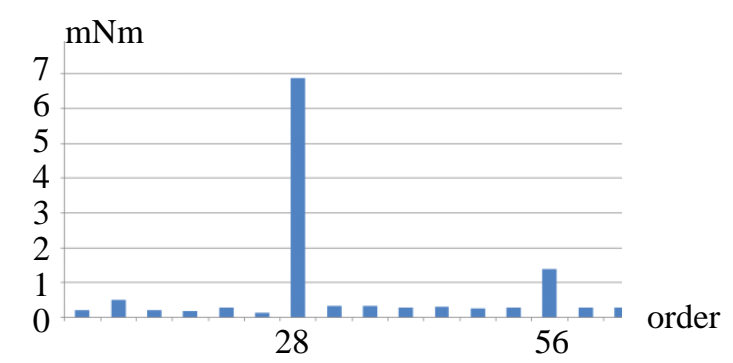

Figure 4.13. Round Square Motor Torque Ripple Fourier (Minimum Current Ripple) 
The optimize target is minimum value of 28 order torque ripple

A

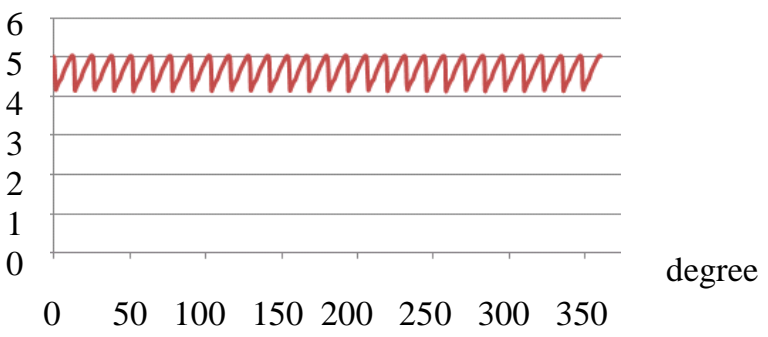

Figure 4.14. Round Square Motor Current Ripple Curve (Minimum Torque Ripple)

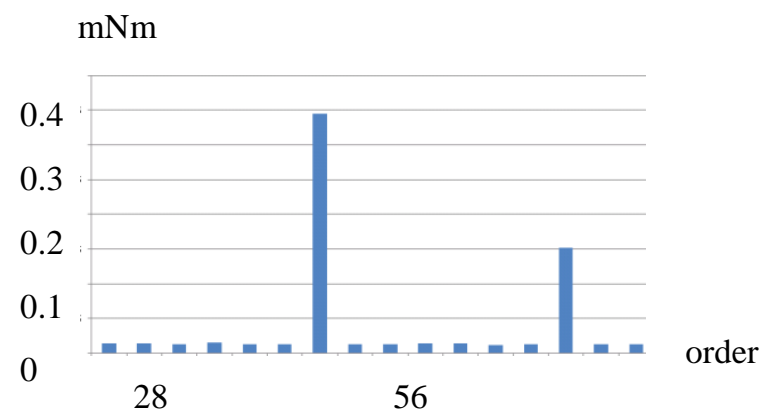

Figure 4.15. Round Square Motor Current Ripple Fourier (inimum Torque Ripple)

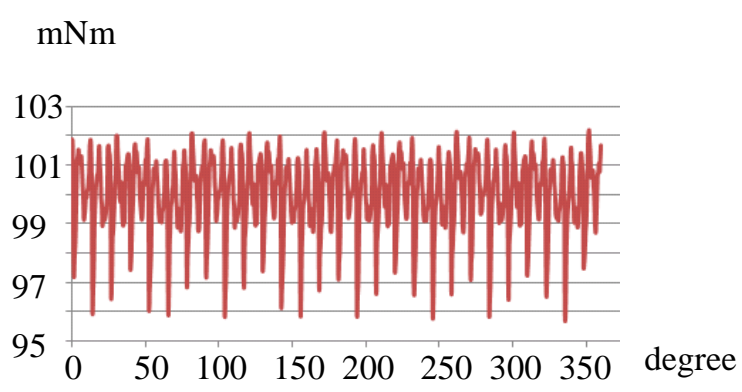

Figure 4.16. Round Square Motor Torque Ripple Curve (Minimum Torque Ripple)

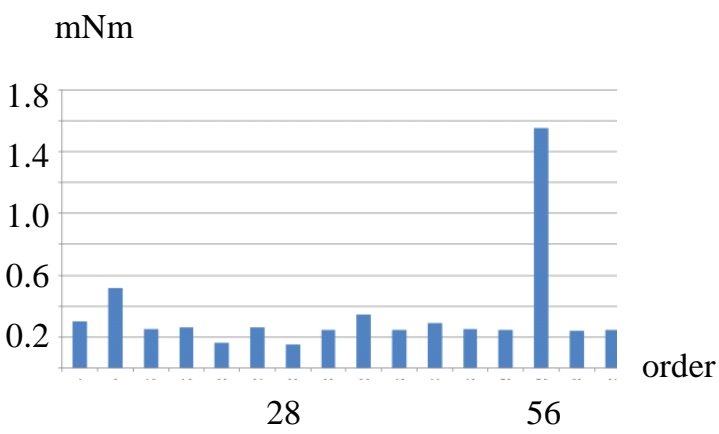

Figure 4.17. Round Square Motor torque Ripple Fourier (Minimum Torque Ripple) 
Analysis the result of before and after 28 order current ripple injection value, when the 28 order harmonic current is minimum, the 28 order torque ripple after harmonic injection is bigger than the value before harmonic injection, then increase the torque ripple, the reason is EMF, the torque ripple impact by current and EMF is converse.

Compare the result of before and after 28 order torque ripple injection, when the current ripple reduce $0.1 \mathrm{~A}$, the torque ripple reduce $2 \mathrm{Nm}$, the torque ripple impact by the EMF and current ripple is same and opposite effect, so the 28 order torque ripple is minimum when the 28 order current ripple is $0.35 \mathrm{~A}$.

Analyze the result of 28 order torque ripple optimization and 28 order current ripple optimization, when the 28 order current ripple is minimum the 28 order torque ripple is not minimum value. When the 28 order current ripple is $0.35 \mathrm{~A}$ the torque ripple is minimum value. Verify the conclusion, the EMF is very critical for the torque ripple.

\section{Conclusion}

For the traditional harmonic method to optimize the torque ripple, it is only focus on the AC and BLDC motor, and can not considered the EMF effect, this paper build the rounded square PMDC motor harmonic injection theoretical model, base on the FEA method to analysis the current and torque ripple. The optimize object is minimum torque and current ripple, compare the torque ripple result of two harmonic injection proposal, Verify the conclusion, the EMF is very critical for the torque ripple. At last, base on the considered the effect of EMF, design the injection harmonic voltage, achieve the minimum value of torque ripple target.

Analysis the relationship between the torque ripple and the initial phase angle, amplitude, frequency of injection harmonic voltage, verify the conclusion, when injection special harmonic voltage the current and torque ripple can achieve the minimum value.

\section{Acknowledgments}

Grateful acknowledgement is made to Johnson electric company who gave me considerable help by means of sample making, testing equipment. In addition, I deeply appreciate the contribution to this thesis made in various ways by my friends and classmates

\section{References}

[1] Z. Zhu, Z. Xia, L. Wu, and G. Jewell, "Analytical modeling and finite-element computation of radial vibration force in fractional-slot permanent-magnet brushless machines," IEEE Trans. Ind. Appl., vol. 46, no. 5, (2010) September/October, pp. 1908-1918.

[2] Z. Zhu, "Improved Analytical Model for Predicting the Magnetic Field Distribution in Brushless Permanent-Magnet Machine”, IEEE TRANSACTIONS ON MAGNETICS, vol. 38, no. 1, (2002) January.

[3] F. Fahy, "Sound and Structural Vibration", UK: Academic Press in an imprint of Elsevier, (2007), pp. 38-64.

[4] Z. Zhu, L. Wu, and G. Jewell, "Comparison of radial vibration forces in 10-pole/12-slot fractional slot surface-mounted and interior PM brushless AC machines," in Proc. 19th ICEM, Rome, Italy, (2010), September, pp. 1-6.

[5] Z. Zhu, Z. Xia, L. Wu, and G. Jewell, "Influence of slot and pole number combination on radial force and vibration modes in fractional slot PM brushless machines having single- and double-layer windings," in Proc. Energy Convers. Congr. Expo., (2009) September, pp. 3443-3450.

[6] Z. Q. Zhu, "Vibration of PM Brushless Machines Having a Fractional Number of Slots per Pole", IEEE Transactions on Magnetics, vol. 42, no. 10, (2006), pp. 1-3.

[7] J. Krotsch, "Radial Forces in External Rotor Permanent Magnet Synchronous Motors with NonOverlapping Windings", IEEE Transactions on Industrial Electronics, vol. 59, no. 5, (2012), pp. 1-8. 
[8] J. O. Fiedler, "Calculation of the Acoustic Noise Spectrum of SRM Using Modal Superposition", IEEE Transactions on Industrial Electronics, vol. 57, no. 9, (2010), pp. 1-4.

[9] D. Franck, "Active reduction of audible noise exciting radial force-density waves in induction motors", 2011 IEEE International Electric Machines \& Drives Conference, (2011), pp. 1-4.

[10] D. Torregrossa and F. Peyraut, "A New Passive Methodology for Reducing the Noise in Electrical Machines: Impact of Some Parameters on the Modal Analysis", IEEE transactions on industry applications, vol. 46, no. 5, (2010), pp. 1899-1905.

[11] J. hong-yun, "Cogging torque compensation for flux-switching permanent magnet motor", Proceedings of CESS, vol. 29, no. 27, (2009), pp. 83-88.

[12] L. Yong, "Torque ripple suppression of permanent magnet synchronous motor by the harmonic injection", Proceedings of CESS, vol. 31, no. 21, (2011), pp. 119-126. 
International Journal of Control and Automation Vol.8, No.5 (2015) 